\title{
POWER SUPPLY AND COOLING SYSTEM FOR HIGH-POWER WATER-COOLED MAGNETS AT
}

\section{TOHOKU UNIVERSITY}

T. Fujioka, Y. Sato, M. Tanabe, A. Hoshi ${ }^{*}$, S. Miura ${ }^{*}$ and Y. Nakagawa ${ }^{*}$

Fusion Technology Development Dept., Toshiba, 13-12 Mita 3-chome, Minato-ku, Tokyo, Japan

${ }^{*}$ The Research Institute for Iron, Steel and Other Metals, Tohoku University, Sendai, Japan

Résumê - Cet article rapporte les essais d'une alimentation de puissance à courant continu et d'un système de refroidissement pour des aimants de haute puissance à refroidissement par eau.

Abstract - The design and test results of a DC power supply and a cooling system for high-power water cooled magnets at Tohoku university are reported.

1. Introduction

At the Research Institute for Ion, Steel and Other metals, Tohoku University, a hybrid magnet project has been under way since 1981. Toshiba corporation has been contributing to this project with the manufacture of hybrid magnets and relevant principal facilities. This paper describes the design and the test of a DC power supply and a cooling system for high-power water-cooled magnets. Details of this project are reported in a separate paper ${ }^{1)}$.

2. DC Powex Supply

The DC power supply consists of two identical $4 \mathrm{MW}\left(350^{\circ} \mathrm{V}-11.5 \mathrm{kA}\right)$ units which may be operated either in parallel or separately depending on the load. One of them was already manufactured and tested successfully to energize a 3.6 MW water-cooled magnet. Another unit is scheduled to be tested at the beginning of 1984 linked with the unit already installed. Principal specifications and a circuit diagram of the system are shown in Table 1 and Fig. 1, respectively.

\subsection{Circuit Diagram}

As shown in Fig. 1, each unit is fed independently from an $\mathrm{AC} 6.6 \mathrm{kV}$ power line through a transformer, which is followed by a 3-phase rectifier bridge with 60 thyristers (SCR), resulting in a fundamental ripple frequency of $300 \mathrm{~Hz}$. To reduce the ripple, both a passive filter and a two-staged active filter are equipped, as described in the next section.

At the $6.6 \mathrm{kV}$ power line, a harmonic filter bank is installed in order to reduce the harmonics produced by SCR. The bank consists of 5 th and 7 th filters, and a highpass filter resonant in 11 th. It is to be noticed that 5 th and 7 th harmonics are nullified in the case of the parallel operation of two units because the connection of transformer is $\Delta-\Delta$ at one unit and $\lambda-\Delta$ at the other unit so as to generate the 12-phase $A C$. This allows for the relatively small capacities of both the 5 th and 7 th filters.

The polarity of the magnet field can be reversed by means of a reversing switch installed at a main busbar, and also a disconnector is installed at each branch busbar for the magnet. Aluminum was chosen as the material of the main busbar from the viewpoint of cost and easy handling for the installation. The power supply can be manipulated by using a remote control panel located at the control room. In addition, an automatic sweep and modulation of the magnet current can be done by means of a computer control.

2.2 DC Filter Design

In the designing of the power supply, the most difficult problem was how to reduce 
the ripple to such a small value as $1 \times 10^{-4} \mathrm{rms}$, while the inductance of the magnet is very small as shown in Table 1. The conventional passive filter with LC circuit is advantageous to reduce relatively high frequency ripples. But it is not suitable to reduce the ripple with such low frequency as $50 \mathrm{~Hz}, 100 \mathrm{~Hz}$ and so on because LC capacity becomes excessively large. Usually these ripples are caused by phase unbalance and/or unbalanced firing timing of SCR. To cope with this difficulty, we used the so-called active filter. There are two types of the active filters: one of them 2) connects many transistors in series with the load, and the other ${ }^{3}$ is to control the ripple at a main circuit by a transister bank of a small capacity at a secondary circuit through a reactor-transformer. The latter was chosen for the present power supply.

As shown in Fig. 1, the transistor bank amplifies alternate components of the voltage as measured at point $A_{1}$ or $A 2$ which are fed into the main circuit with opposite phase via a reactor-transformer $L_{1}$ or $\mathrm{L}_{2}$, compensating any deviations up to $1 \times 10^{-4} \mathrm{rms}$. The gain required for this active filter is designed to be about 30 $\mathrm{dB}$ being too large to be attained by a one-staged active filter without the occurrence of hunting due to detection errors. Then a two-staged active filter

Table 1 Specifications of DC Power Supply

\begin{tabular}{|lll|}
\hline Primary voltage & AC $6.6 \mathrm{KV}$ & \\
Secondary voltage & DC $0-350 \mathrm{~V}$ & \\
Secondary current & DC $0-23 \mathrm{KA}$ & (two units in parallel) \\
Secondary power & $8 \mathrm{MW} \quad$ (two units in parellel) \\
Current stability & $\leq 1 \times 10^{-4} / 3 \mathrm{hr} \quad$ (at full power) \\
Current ripple & $\leqslant 1 \times 10^{-4} \mathrm{rms} \quad$ (at full power) \\
Linearity of sweep & $\therefore 1 \times 10^{-2} \quad$ (at current of $\left.5 \% \sim 95 \%\right)$ \\
Magnet parameter & $\mathrm{R}=15 \sim 35 \mathrm{~m} \Omega$ \\
& $\mathrm{L}=0.3 \sim 1.3 \mathrm{mH}$ \\
\hline
\end{tabular}
is designed. It is to be emphasized that not a 12-pu1se, but only a 6-pu1se SCR is designed, because the ripples with higher frequency than $300 \mathrm{~Hz}$ are not so dominating factors in the DC filter design as compared with the low frequency ripples mentioned above.

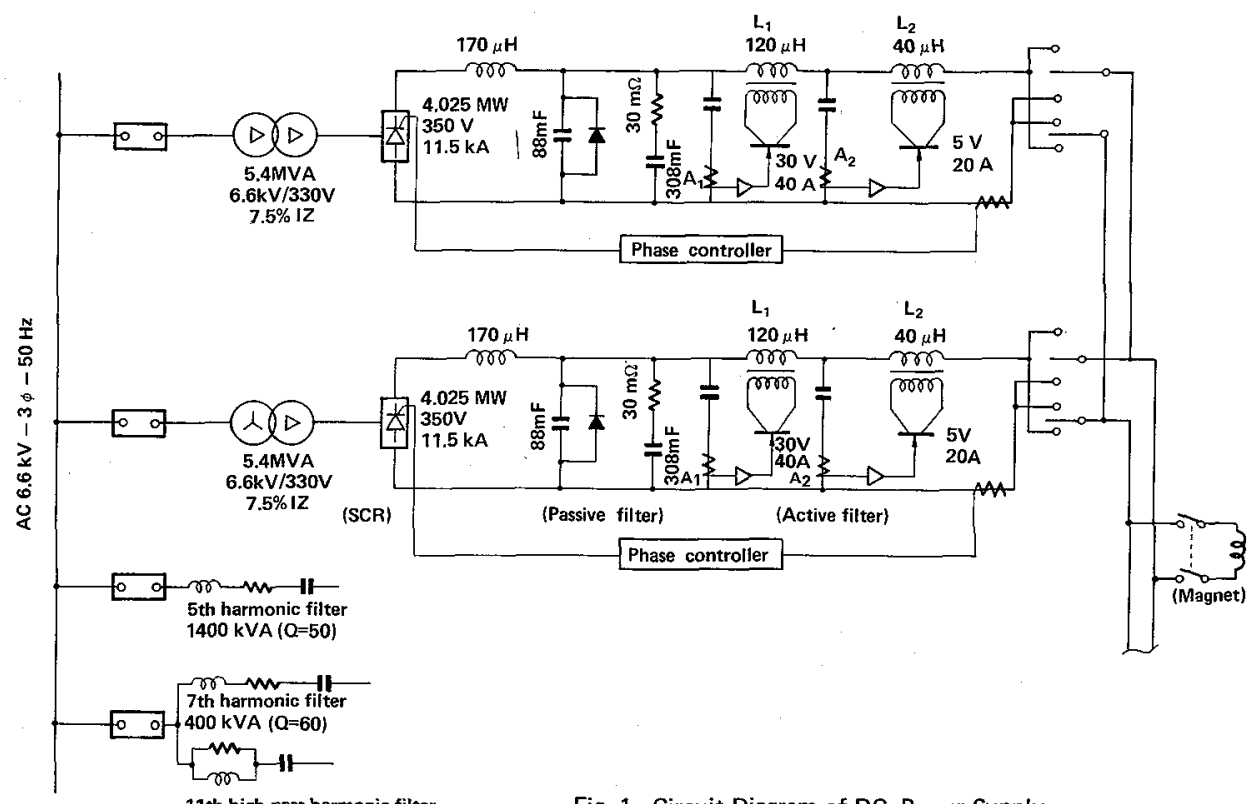

2.3 Tests Results

The test results satisfied the specifications listed in Table 1 . The ripples with higher frequency than $50 \mathrm{~Hz}$ were small enough. In some case, however, rather large ripples of low frequency $(5 \sim 7 \mathrm{~Hz})$ were observed as shown in Fig. 2. Such Low frequency ripples were considered to be caused by external noise in the $A C$ power line because it always appears whenever and only when the same low frequency components were found at the primary voltage. On the other hand, harmonics of 
5 th, 7 th, 11 th, 13 th and so on produced in the AC line by the SCR were measured and confirmed to be within permitted values.

3. Cooling System

The purpose of the cooling system is to remove a vast amount of Joule loss dissipated in the magnet and also to cool all of the DC power supplies used for the hybrid magnets. The total cooling capacity of $6 \mathrm{MW}$ is obtained by two identical sets consisting of a turbo-refrigerator, a cooling tower and relevant pumps. One set was already manufactured and tested successfully to cool the magnet. Like

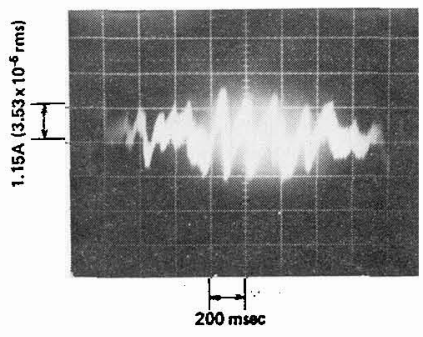

Fig. 2 Photo of Ripple at $11.5 \mathrm{KA}$

the DC power supply, another set now being manufactured in scheduled to be tested soon. Principal specifications and a circuit diagram of the system are shown in Table 2 and Fig. 3, respectively. It is to be noticed chat this system differs from that of MIT or Grenoble where the Joule loss is finally transferred into the river water. In the present system, the cooling capacity of 6 MW can be maintained with water temperature of about $6^{\circ} \mathrm{C}$ even in summer.

\subsection{Circuit Diagram}

The system is composed of a primary circuit with deionized water which cools the magnets after being chilled by refrigerators, and a secondary circuit with city water which cools as a condensing circuit of the refrigerators.

\subsubsection{Primary Circuit}

The deionized water is directly chilled below $10^{\circ} \mathrm{C}$ by the refrigerators $R_{1}$ and $R_{2}$, and stored in a $200 \mathrm{~m}^{3}$ tank DT. Then it is pressurized by four circulation pumps $\mathrm{P}_{1} \sim \mathrm{P}_{4}$ (75 $\mathrm{kW}$ each) up to the pressure of about $20 \mathrm{~kg} / \mathrm{cm}^{2}$, and supplied to the magnets WMI WM7. The resistivity of water is kept over $1 \mathrm{M} \Omega . \mathrm{cm}$ by an ionexchanger IE. The DC power supplies $\mathrm{PS}_{1} \sim \mathrm{PS}_{5}$ are cooled indirectiy by this chilled water through a heat exchanger $\mathrm{HE}$ to avoid dew condensing in them especially during the wet and cold season.

\subsubsection{Secondary Circuit}

The cooling towers $\mathrm{CT}_{1}$ and $\mathrm{CT}_{2}$ of so-called open type are to cool the city water which is once stored in a tank WT and circulates through the condensors of the refrigerators. The Joule loss of the magnet is once converted thermodynamically into the enthalpy of Freon in the refrigerators and finally dissipated as the evaporation heat of water in the cooling towers.

3.2 Characteristics of the System

Refrigerators: They can chill the deionized water directly so as to improve the cooling efficiency of the system. Each refrigerator has two compressors in parallel, and their capacities are automatically controlled to keep the water temperature between $6^{\circ} \mathrm{C} \sim 10^{\circ} \mathrm{C}$ without frequent start/stop operations.

Deionized water tank: Its capacity of $200 \mathrm{~m}^{3}$ enables us to energize the magnet with the power over $6 \mathrm{MW}$ (rated cooling capacity) for a short time. It is to be noted that rated DC power is $8 \mathrm{MW}$.

Cooling towers: They are designed to be low-noise type and moreover a sound proof barrier of about $11 \mathrm{~m}$ height was constructed around them. To reduce the noise further at night, their fans' speed is changed from 1000 rpm to 750 rpm by means of pole-change of the motor; the cooling capacity at night is not so different from that of daytime, because of lower temperature at night. Also they are designed to suppress the fog to be produced in the air.

Circulation pump: One of four pumps is speed-controlled by transistor inverter in order to adjust the flow rate continuously and also to make an air-venting operation of the primary circuit smoothly. 
Table 2 Specification of Cooling System

\begin{tabular}{|c|c|c|c|}
\hline Primary eircuit & & econdary circuit & \\
\hline Flow rate for magnet & $350 \mathrm{~m}^{3} / \mathrm{hr}$ & Cooling capacity of cooling tower & \\
\hline Delivery pressure of pump for magnet & $20 \mathrm{~kg} / \mathrm{cm}^{2}$ & at wet bulb temperature of $25^{\circ} \mathrm{C}$ & $7.4 \mathrm{MW}$ \\
\hline inlet temperature for magnet & $6^{\circ} \mathrm{C} \sim 10^{\circ} \mathrm{C}$ & Capacity of city water tank & $100 \mathrm{~m}^{3}$ \\
\hline Resistivity of cooling water & $>1 \mathrm{M} \Omega \cdot \mathrm{cm}$ & Flow rate of supplied water & $12 \mathrm{~m}^{3} / \mathrm{hr}$ \\
\hline Cooling capacity of turbo-refrigerators & $6 \mathrm{MW}$ & & \\
\hline Capacity of deionized water tank & $200 \mathrm{~m}^{3}$ & & \\
\hline Flow rate for DC power supplies & $36 \mathrm{~m}^{2} / \mathrm{hr}$ & & \\
\hline Inlet temperature for DC power supplies & $25^{\circ} \mathrm{C}$ & & \\
\hline
\end{tabular}

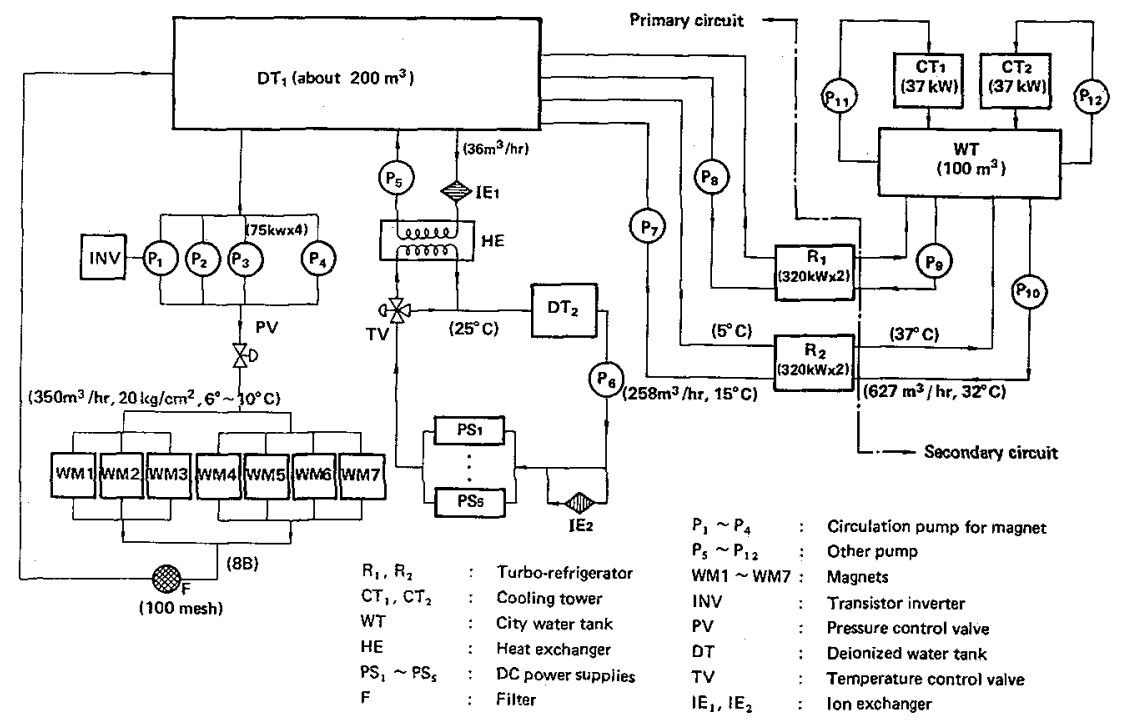

Fig. 3 Diagram of Cooling System

\section{3 Test Results}

The cooling capacity of the refrigerator and the cooling tower were confirmed to satisfy specifications in the test where the magnet was energized with 3 MW continuously for a sufficiently long time. Also they could be controlled to start/stop periodically in several ten minutes, maintaining the temperature of the inlet water to the magnet between $6^{\circ} \mathrm{C}$ and $10^{\circ} \mathrm{C}$. The noise produced by the cooling tower was confirmed to be much less than the permitted value.

\section{Acknowledgements}

The authors express their thanks to Professor Y. Muto, Dr. K. Noto and Mr. K. Watanabe of Tohoku University for their cooperation in the present project. Thanks are also due to Dr. J. Nagamura and Mr. S. Ichikawa of Toshiba.

\section{References}

1) Y. Nakagawa, K. Noto, A. Hoshi, S. Miura, K. Watanabe and Y. Muto: This Conference 4E $2-01$.

2) K. van Hulst, C.J.M. AARTS, A.R. de Vroomen and P. Wyder: J. Magn. Magn. Mater. 11 (1979) 317

3) J.C. Picoche, P. Rub, J.C. Vallier and H.J. Schneider-Muntau: J. Magn. Magn. Mater. 11 (1979) 308 